\title{
A PROSPECTIVE STUDY ON FOETOMATERNAL OUTCOME IN CASES OF PREGNANCY WITH HEART DISEASES IN A TERTIARY HOSPITAL
}

\author{
Shyamal Dasgupta1, Poushali Sanyal2, Jhuma Biswas ${ }^{3}$, Chiranjit Ghosh ${ }^{4}$, Sandip Sengupta ${ }^{5}$, Shubhashis Samajder6, Asmita Jadhav , \\ Varsha Saboo ${ }^{8}$
}

\begin{abstract}
${ }^{1}$ Associate Professor, Department of Obstetrics and Gynaecology, Institute of Post Graduate Medical Education and Research, Kolkata. ${ }^{2}$ Clinical Tutor, Department of Obstetrics and Gynaecology, Institute of Post Graduate Medical Education and Research, Kolkata. ${ }^{3}$ Assistant Professor, Department of Obstetrics and Gynaecology, Institute of Post Graduate Medical Education and Research, Kolkata. ${ }^{4}$ Clinical Tutor, Department of Obstetrics and Gynaecology, Institute of Post Graduate Medical Education and Research, Kolkata. ${ }^{5}$ Assistant Professor, Department of Obstetrics and Gynaecology, Institute of Post Graduate Medical Education and Research, Kolkata. 6Junior Resident, Department of Obstetrics and Gynaecology, Institute of Post Graduate Medical Education and Research, Kolkata. 7 Junior Resident, Department of Obstetrics and Gynaecology, Institute of Post Graduate Medical Education and Research, Kolkata. ${ }^{8}$ Senior Resident, Department of Obstetrics and Gynaecology, Institute of Post Graduate Medical Education and Research, Kolkata.
\end{abstract}

\begin{tabular}{l}
\hline ABSTRACT \\
BACKGROUND \\
ardiac diseases comprise almost 4\% of pregnancies in women in India. There is a risk of pregnant women with both congenital \\
mother and baby. \\
Objective- Our study was aimed at identifying pregnancies with congenital and acquired heart diseases, to assess the effect of heart \\
diseases on maternal, foetal and neonatal health.
\end{tabular}

\section{MATERIALS AND METHODS}

The study was a prospective observational study carried out on 40 patients in IPGMER over a one-year period. All patients were subjected to detailed history taking and clinical examination and investigations. The mode of delivery, period of gestation, antenatal, intranatal and postnatal complications were calculated as well as the detailed history of delivery of the baby and neonatal parameters like birth weight, and APGAR score were assessed.

\section{RESULTS}

29 patients had acquired heart disease while 11 had congenital heart disease. Among the CHD group 7 developed heart failure. Cardiological complications as well as maternal mortality were higher in the AHD group than CHD group. LBW and preterm delivery were more common among AHD group but congenital heart lesion was more common among CHD patients. Mode of delivery did not differ in the two groups.

\section{CONCLUSION}

A high index of suspicion and vigilant interdisciplinary approach can optimise the foetomaternal outcome in pregnant women with heart disease.

\section{KEYWORDS}

Pregnancy, Heart Disease, Congenital, Acquired.

HOW TO CITE THIS ARTICLE: Dasgupta S, Sanyal P, Biswas J, et al. A prospective study on foetomaternal outcome in cases of pregnancy with heart diseases in a tertiary hospital. J. Evolution Med. Dent. Sci. 2018;7(01):16-19, DOI: 10.14260/jemds/2018/5

\section{BACKGROUND}

Cardiac diseases complicate $1 \%$ to $4 \%$ of pregnancies in women. ${ }^{1}$ Pregnancy with heart disease is a challenging problem to obstetricians as well as cardiologists as marked haemodynamic changes in pregnancy and cardiac output in particular, have profound effects on heart disease. Rheumatic heart disease (RHD) is the commonest cause of heart disease during pregnancy, followed by congenital heart disease (CHD). Amongst RHD, the predominant lesion is Mitral Stenosis, while Atrial Septal Defect (ASD) remains the most

'Financial or Other Competing Interest': None.

Submission 19-11-2017, Peer Review 12-12-2017,

Acceptance 19-12-2017, Published 01-01-2018.

Corresponding Author:

Poushali Sanyal,

\#192/A, Shyama Prasad Mukherjee Road,

Kolkata-700026.

E-mail: poushali.sanyal@yahoo.co.in

DOI: $10.14260 /$ jemds $/ 2018 / 5$

\section{(c) (i) $(9)$}

common lesion amongst CHDs. RHD, once responsible for the majority of cardiac cases in pregnancy, is now declining, owing to better treatment administered for prophylaxis of rheumatic fever, improving socioeconomic status, and better availability of specialist care as well as higher index of suspicion among physicians towards rheumatic fever as compared to previous decades. ${ }^{2}$

In the United Kingdom about 250000 adults have congenital heart disease (also known as "Grown up Congenital Heart Disease "or GUCH), and this number is growing. 3 Similar trend has been observed in India. The medical profession should be aware of the risks that women with congenital heart disease face during pregnancy, so that they can be given adequate preconception counselling and optimal care during pregnancy, delivery, and the postpartum period. The risk for pregnant women with congenital heart disease of having adverse cardiovascular events is determined by the ability of their cardiovascular system to adapt to the physiological changes of pregnancy. 
Overall, there is a higher incidence of foetal and neonatal adverse events - including intrauterine growth restriction, premature birth, intracranial haemorrhage, and foetal loss in women with heart disease compared with the general population. 4 This risk is highest in women with poor functional class, cyanosis and left heart obstruction, and is amplified by any other obstetric risk factors.

We conducted this study to identify the pregnancies with heart diseases consequent to congenital and acquired heart diseases. We also tried to assess the effect of these heart diseases on maternal as well as neonatal outcome in these women.

\section{MATERIALS AND METHODS}

The study was a prospective observational study conducted over a one-year period (February 2013 to January 2014) on patients admitted in the Department of Obstetrics and Gynaecology and the Department of Cardiology of IPGMER and SSKM hospital. A total of 40 cases were studied. All pregnant women with congenital and acquired heart diseases with special reference to heart failure carrying singleton as well as multiple pregnancy, irrespective of age group and gestation were included in the study. Patients with any other medical or surgical complications were excluded from the study. A clearance from the institutional ethics committee was obtained prior to conducting the study.

All patients were subjected to detailed history taking followed by general, systemic and local examination. Patients were selected on the basis of clinical parameters and other investigations. Effects of heart diseases on foetomaternal health such as maternal symptoms in pregnancy, antenatal, intranatal and postnatal complications, mode of delivery, and gestational age at delivery, were judged. The ultimate result obtained, was tabulated, analysed and evaluated.

\section{RESULTS}

In our study, all data obtained were properly arranged and statistically tabulated. These data were analysed using the SPSS package. The software used was Statistica Version 6.0. We arranged the data in different tables and charts.

From the Table 1 and Chart 1 it is apparent that out of 40 patients, $11(27.5 \%)$ patients have congenital heart disease and 29 patients $(72.5 \%)$ have acquired heart disease. Out of 11 patients of congenital heart diseases, only 1 patient (9.09\%) was below 20 years of age and majority (90.9\%) were in 21-30 years of age group. In acquired heart disease group, 7 patients $(24.13 \%)$ were below 20 years of age. 19 patients $(65.5 \%)$ were in between 21-30 years of age. Only 3 patients $(10.3 \%)$ were in between $31-40$ years of age. So, overall, $72.5 \%$ of the study population was between $21-30$ years of age. Mean age of the whole cohort was 24.5 where minimum age was 18.0 and maximum 35.0 with standard deviation 4.19 .

In the CHD group, 5 , that is $45.45 \%$ were primi while 6 $(54.54 \%)$ were multigravidae. In the acquired heart disease group, $14(48.27 \%)$ were primi whereas 15 (51.72\%) were multigravidae. The difference in gravidity is not statistically significant. Amongst the CHD patients, 5 out of 11 , or $45 \%$ had ASD and 6 had VSD (55\%), whereas, among the 29 patients of Acquired heart disease group, 24 (83\%) had Mitral Stenosis, 3 (10\%) had Mitral Regurgitation and 2 (7\%) had Dilated Cardiomyopathy.
Table 2 and Chart 2 shows that CHD patients mostly present with dyspnoea (18.18\%) and palpitation (18.18\%), and acquired heart disease patients chiefly met with dyspnoea (58.6\%).

Table 3 shows that only 1 patient [9.09\%] of CHD developed cardiac complication (infective endocarditis) whereas 18 out of 29 patients of AHD (62.06\%) developed several cardiac complications [Heart failure $=7$ pts., Atrial fibrillation $=4$ pts., Pulmonary arterial hypertension $=4$ pts., Arrhythmia $=3$ pts.,]. So patients with acquired heart disease mostly emerge with several cardiac complications (62.06\%) during the study period, in comparison with CHD.

Only 1 patient of CHD had anaemia in pregnancy whereas 8 patients in the acquired heart disease category, or $27.58 \%$ had anaemia in pregnancy. Comparison of LVEF\% among CHD and AHD group shows that the majority of patients of both groups (CHD - 72.72\% and AHD - 72.41\%) had their ejection fraction more than $60 \%$. Table 4 shows the details of gestational age at which foetuses delivered in the CHD and AHD group. 9 (81.81\%) among CHD patients delivered between 37-40 weeks, whereas 21 (72.41\%) of AHD patients delivered in between 37-40 weeks. Table 5 shows 5 patients [45.45\%] of CHD delivered vaginally and 5 patients [45.45\%] delivered by LSCS whereas 11 patients [37.93\%] of AHD delivered vaginally and 11 patients [37.93\%] delivered by lower segment caesarean section.

Table 6 shows no LBW baby born in CHD group whereas 5 [17.24\%] babies in AHD group fall into LBW category. 4 [13.79\%] babies were born preterm in AHD group and 1 baby [9.09\%] in CHD group. 2 babies [6.89\%] in AHD group shows APGAR <7. One baby out of 11 patients of CHD showed congenital lesion of heart by foetal echo. 2 babies died in utero in AHD group, and got delivered by PMCS.

3 maternal deaths were reported in AHD group, whereas no maternal mortality was noted in CHD group. This difference is statistically not significant, but a trend is present. Hence, maternal mortality is more commonly present in those with heart failure.

\begin{tabular}{|c|c|c|}
\hline Age & $\begin{array}{c}\text { Congenital Heart } \\
\text { Disease (n=11) }\end{array}$ & $\begin{array}{c}\text { Acquired Heart } \\
\text { Disease (n=29) }\end{array}$ \\
\hline$<20$ yrs. & $1(9.09 \%)$ & $7(24.13)$ \\
\hline $21-30$ yrs. & $10(90.9 \%)$ & $19(65.5 \%)$ \\
\hline $31-40$ yrs. & - & $3(10.3 \%)$ \\
\hline$>40$ yrs. & - & - \\
\hline \multicolumn{3}{|c|}{ Table 1. Age Distribution } \\
\hline
\end{tabular}

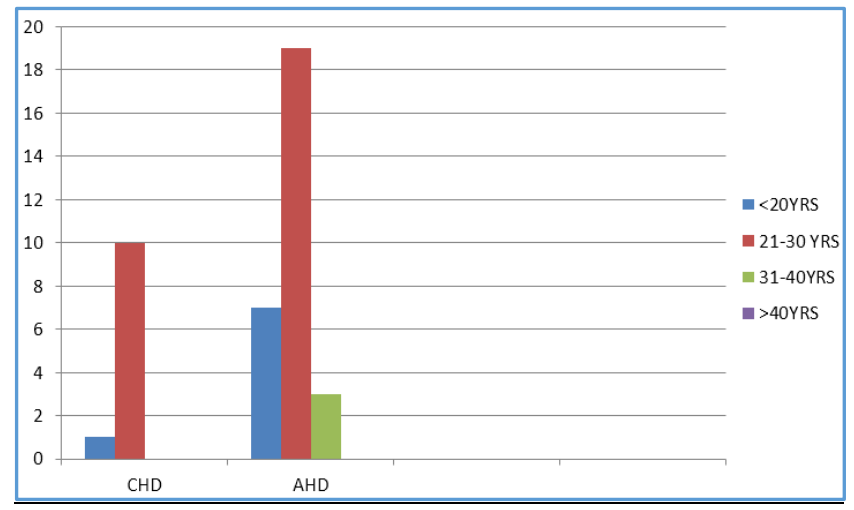

Chart 1. Distribution of Congenital and Acquired Heart Diseases among Various Age Group 


\begin{tabular}{|c|c|c|}
\hline Symptoms & CHD [n=11] & AHD [n=29] \\
\hline Dyspnoea & $2[18.18 \%]$ & $17[58.62 \%]$ \\
\hline Cough & - & $4[13.79 \%]$ \\
\hline Chest pain & $1[9.09 \%]$ & $6[20.68 \%]$ \\
\hline Palpitation & $2[18.18 \%]$ & $13[44.82 \%]$ \\
\hline
\end{tabular}

Table 2. Comparison of Symptoms between CHD \& AHD Population

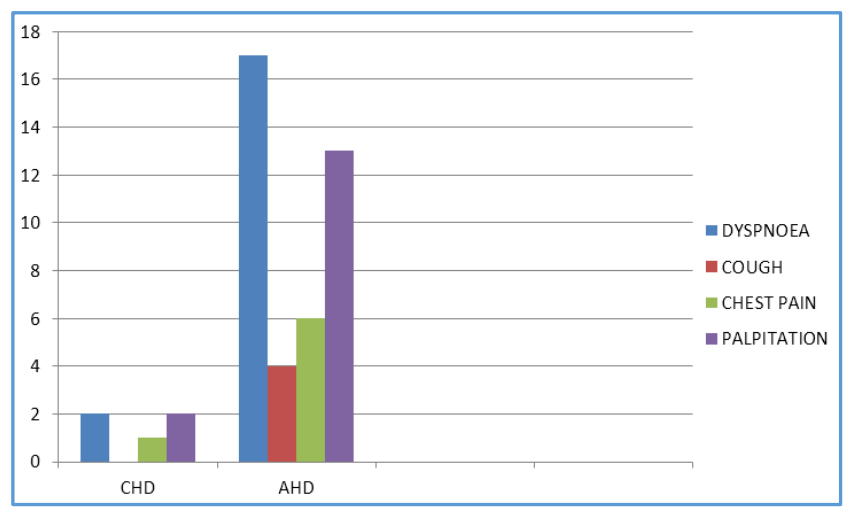

Chart 2. Comparison of Symptomatology in CHD \& AHD

\begin{tabular}{|c|c|c|}
\hline Cardiac Comp. & CHD [n=11] & AHD [n=29] \\
\hline Infective Endocarditis & $1[9.09 \%]$ & - \\
\hline Atrial Fibrillation & - & $4[13.79 \%]$ \\
\hline Arrhythmia & - & $3[10.34 \%]$ \\
\hline Pul.Art.HT & - & $4[13.79 \%]$ \\
\hline Heart Failure & - & $7[24.13 \%]$ \\
\hline \multicolumn{2}{|c|}{ Table 3. Cardiac Complications among } \\
CHD \& AHD Patients
\end{tabular}

\begin{tabular}{|c|c|c|}
\hline Gestational Age at DEL. & CHD [n=11] & AHD [n=29] \\
\hline$<34$ weeks & 0 & $1[3.44 \%]$ \\
\hline $34-<37$ weeks & $1[9.09 \%]$ & $4[13.79 \%]$ \\
\hline $37-40$ weeks & $9[81.81 \%]$ & $21[72.41 \%]$ \\
\hline$>40$ weeks & $1[9.09 \%]$ & $3[10.34 \%]$ \\
\hline \multicolumn{2}{|c|}{ Table 4. Gestational Age at Delivery in } \\
CHD \& AHD Patients \\
\hline
\end{tabular}

\begin{tabular}{|c|c|c|}
\hline Delivery Mode & CHD [n=11] & AHD [n=29] \\
\hline Vaginal & $5[45.45 \%]$ & $11[37.93 \%]$ \\
\hline Forceps & $1[9.09 \%]$ & $7[24.13 \%]$ \\
\hline LSCS & $5[45.45 \%]$ & $11[37.93 \%]$ \\
\hline \multicolumn{3}{|c|}{ Table 5. Various Modes of Delivery among } \\
CHD \& AHD Patients \\
\hline
\end{tabular}

\begin{tabular}{|c|c|c|}
\hline Foetal \& Neonatal Outcome & CHD [n=11] & AHD [n=29] \\
\hline Low Birth Weight $[<2.5 \mathrm{~kg}]$ & 0 & $5[17.24 \%]$ \\
\hline Foetal Maturity <37 weeks & $1[9.09 \%]$ & $4[13.79 \%]$ \\
\hline APGAR $<7$ & $1[9.09 \%]$ & $2[6.89 \%]$ \\
\hline Congenital Lesion of Heart & $1[9.09 \%]$ & 0 \\
\hline Neonatal Mortality & 0 & $2[6.89 \%]$ \\
\hline \multicolumn{3}{|c|}{$\begin{array}{c}\text { Table 6. Foetal and Neonatal Outcome in } \\
\text { CHD \& AHD Patients }\end{array}$} \\
\hline
\end{tabular}

\section{DISCUSSION}

With the advent of modern technique, haemodynamics in pregnancy is better understood. The management of heart disease in pregnancy has become more methodical than it was years ago. But still, heart disease especially when complicated by heart failure is one of the leading causes of maternal mortality in our country.

Our study showed that $27.5 \%$ patients had CHD and $72.5 \%$ had AHD. Among CHD group VSD (55\%) was predominant and MS constituted the major part (83\%) of AHD. The results are similar to the study by Venkatramana ${ }^{5}$ et al.

It was seen that CHD and AHD both were more common in multigravida, which was similar to the study by Avila et al, ${ }^{6}$ but differed from the study by Siu et al. ${ }^{4}$

Regarding the presenting symptoms, CHD patients mostly presented with dyspnoea (18.18\%), and palpitation (18.18\%), whereas AHD patients chiefly met with dyspnoea (58.6\%). This was similar to the study by Khairy P et al ${ }^{6}$ and Avila et al. ${ }^{7}$

Our study showed that preterm delivery was more common among AHD group (17.23\%) than the CHD group (9.09\%). Mean gestational age at delivery in the entire cohort was $268.1 \pm 11.82$ days, which corresponded to the study by Koregol et al. ${ }^{8}$

In our study, among the 11 babies born to the CHD patients, no baby was of low birth weight, 1 (9.09\%) baby had birth asphyxia, 1 baby had a congenital heart lesion. Among the babies born to the 29 AHD mothers, 5 (17.24\%) were low birth weight, 2 (6.89\%) suffered from birth asphyxia, and 2 (6.89\%) died after birth. These results were similar to the studies by $\mathrm{Siu}^{4}$ and Avila et al. ${ }^{7}$

Overall $40 \%$ delivered vaginally and $40 \%$ by LSCS, and $20 \%$ by forceps. Mode of delivery did not differ in the CHD and AHD group but most of the patients with heart failure delivered by LSCS (71.42\%) which was not statistically significant. WS Avila ${ }^{6}$ found that $65 \%$ patients delivered vaginally whereas $35 \%$ delivered by LSCS.

In our study, the overall maternal mortality rate was $7.5 \%$. All 3 deaths occurred in the Acquired heart disease category. This was much more in comparison to the studies by Avila et al, 7 who found a maternal mortality rate of $2.7 \%$. This difference can be attributed to the ethnicity of the population and the presence of heart failure in 2 out of the 3 cases.

\section{CONCLUSION}

Pregnancy complicated with heart disease is a grave condition for both the mother and child. In the presence of maternal heart disease, the circulatory changes of pregnancy may result in adverse consequences, including the death of the mother and foetus. ${ }^{4}$ Management of pregnant women with pre-existing cardiac problems should be undertaken by multidisciplinary teams in tertiary centres. In women with pre-existing cardiac disease wishing to proceed to term, cardiac status must be optimised prior to delivery and preferably a planned elective delivery should be scheduled. ${ }^{9}$ It can be concluded from the present study that a high index of suspicion and vigilant interdisciplinary approach can optimise the foetomaternal outcome in pregnant women with heart disease.

\section{ACKNOWLEDGEMENT}

We wish to thank Professor T.K. Ghosh, ex Head of the Department of Obstetrics and Gynaecology, IPGMER, for his support while conducting the study. 


\section{REFERENCES}

[1] Dobbenga-Rhodes YA, Prive AM. Assessment and evaluation of the women with cardiac disease during pregnancy. J Perinat Neonatal Nurs 2006;20(4):295302.

[2] Asafeh JM, Baird SM. Cardiac disease in pregnancy. Crit Care Nurs Q 2006;29(1):32-52.

[3] Elkayam U, Bitar F. Valvular heart disease in pregnancy part I: native valves. J Am Coll Cardiol 2005;46(2):223-30.

[4] Siu SC, Colman JM, Sorensen S, et al. Adverse neonatal and cardiac outcomes are more common in pregnant women with cardiac disease. Circulation 2002;105(18):2179-84.
[5] Venkatramana. J Obs \& Gynae Ind 1986;36:973-7.

[6] Khairy P, Ouyang DW, Fernandes SM, et al. Pregnancy outcomes in women with congenital heart disease. Circulation 2006;113(4):517-24.

[7] Avila WS, Rossi EG, et al. Pregnancy in patients with heart disease: experience with 1,000 cases. Clin Cardiol 2003;26(3):135-42.

[8] Koregol M, Mahale N, Nayak R, et al. Maternal and perinatal outcomes of pregnancies complicated by cardiac disease Maternal Cardiac Diseases and Pregnancy. J Turkish-German Gynecol Assoc 2009;10:30-4.

[9] Ray P, Murphy GJ, Shutt LE. Recognition and management of maternal cardiac disease in pregnancy. Br J Anaesth 2004;93(3):428-39. 